



\section{Watergebruik in de land- en tuinbouw 2017 en 2018}

R.W. van der Meer 
R.W van der Meer, 2020. Watergebruik in de land-en tuinbouw 2017 en 2018. Wageningen, Wageningen Economic Research, Nota 2020-030. 22 blz.; 1 fig.; 5 tab.; 5 ref.

Deze notitie beschrijft hoe het watergebruik in de land- en tuinbouw, uitgesplitst naar

7 stroomgebieden, wordt berekend. De resultaten van de berekeningen dienen als input voor de CBSpublicaties Milieurekeningen, Monitor Brede Welvaart en het Compendium voor de Leefomgeving. De basis van de berekeningen wordt gevormd door de resultaten van de bedrijven uit het Bedrijveninformatienet van Wageningen Economic Research. Voor het aggregeren van de bedrijfsresultaten naar sectoren en stroomgebieden is gebruikgemaakt van statistical matching.

Trefwoorden: watergebruik, land- en tuinbouw, bedrijveninformatienet, statistical matching

Deze nota is gratis te downloaden op https://doi.org/10.18174/519864 of op www.wur.nl/economicresearch (onder Wageningen Economic Research publicaties).

(C) 2020 Wageningen Economic Research

Postbus 29703, 2502 LS Den Haag, T 07033583 30, E communications.ssg@wur.nl, www.wur.nl/economic-research. Wageningen Economic Research is onderdeel van Wageningen University \& Research.

\section{(cc) BY-NC}

Dit werk valt onder een Creative Commons Naamsvermelding-Niet Commercieel 4.0 Internationaallicentie.

(C) Wageningen Economic Research, onderdeel van Stichting Wageningen Research, 2020

De gebruiker mag het werk kopiëren, verspreiden en doorgeven en afgeleide werken maken. Materiaal van derden waarvan in het werk gebruik is gemaakt en waarop intellectuele eigendomsrechten berusten, mogen niet zonder voorafgaande toestemming van derden gebruikt worden. De gebruiker dient bij het werk de door de maker of de licentiegever aangegeven naam te vermelden, maar niet zodanig dat de indruk gewekt wordt dat zij daarmee instemmen met het werk van de gebruiker of het gebruik van het werk. De gebruiker mag het werk niet voor commerciële doeleinden gebruiken.

Wageningen Economic Research aanvaardt geen aansprakelijkheid voor eventuele schade voortvloeiend uit het gebruik van de resultaten van dit onderzoek of de toepassing van de adviezen.

Wageningen Economic Research is ISO 9001:2015 gecertificeerd.

Wageningen Economic Research Nota 2020-030 | Projectcode 2282200523

Foto omslag: Shutterstock 


\section{Inhoud}

Samenvatting $\quad \mathbf{5}$

S.1 Uitkomsten $\quad 5$

S.2 Verantwoording $\quad 5$

$1 \quad$ Inleiding $\quad 6$

1.1 Aanleiding 6

1.2 Resultaat 6

$\begin{array}{lll}1.3 & \text { Afbakening } & 6\end{array}$

$\begin{array}{llr}2 & \text { Methodiek } & 7\end{array}$

$\begin{array}{lll}2.1 & \text { Inleiding } & 7\end{array}$

$\begin{array}{lll}2.2 & \text { Bedrijfstypen en stroomgebieden } & 7\end{array}$

2.3 Statistical matching $\quad 8$

2.4 Bijschatting 9

2.5 Drenking vee $\quad 9$

$\begin{array}{lr}\text { Uitkomsten } & 10\end{array}$

$\begin{array}{lll}3.1 & \text { Totaal watergebruik land- en tuinbouw } & 10\end{array}$

$\begin{array}{ll}3.2 \text { Watergebruik per bedrijf } & 11\end{array}$

$\begin{array}{lll}3.3 & \text { Beregend areaal } & 12\end{array}$

$\begin{array}{ll}\text { Literatuur en websites } & 13\end{array}$

$\begin{array}{lll}\text { Bijlage } 1 \text { Watergebruik vanaf } 2001 & 14\end{array}$

Bijlage 2 Watergebruik naar sector en stroomgebied 15

Bijlage $3 \quad$ Watergebruik per bedrijf $\quad 19$

$\begin{array}{lll}\text { Bijlage } 4 & \text { Statistical matching } & 20\end{array}$ 



\section{Samenvatting}

\section{S.1 Uitkomsten}

- In 2018 is er een recordhoeveelheid water gebruikt op land- en tuinbouwbedrijven: 350 miljoen $\mathrm{m}^{3}$. Dit is het gevolg van de extreme droogte in 2018. In 2017 was het watergebruik bijna 170 miljoen $\mathrm{m}^{3}$.

- Het leidingwatergebruik per bedrijf lag in 2018 ook hoger dan ooit. De stijging ten opzichte van 2017 was echter beperkt tot ongeveer $20 \mathrm{~m}^{3}$ per bedrijf. Het totale watergebruik per bedrijf verdubbelde tot $6.500 \mathrm{~m}^{3}$ in 2018 .

- Voor de beregening is hoofdzakelijk grondwater gebruikt.

\section{S.2 Verantwoording}

Deze notitie beschrijft hoe het watergebruik in de land- en tuinbouw, uitgesplitst naar 7 stroomgebieden, wordt berekend. De resultaten van de berekeningen dienen als input voor de CBSpublicaties Milieurekeningen, Monitor Brede Welvaart en het Compendium voor de Leefomgeving. De basis van de berekeningen wordt gevormd door de resultaten van de bedrijven uit het Bedrijveninformatienet van Wageningen Economic Research. Voor het aggregeren van de bedrijfsresultaten naar sectoren en stroomgebieden is gebruik gemaakt van statistical matching. 


\section{$1 \quad$ Inleiding}

\section{$1.1 \quad$ Aanleiding}

In de land- en tuinbouw wordt leidingwater gebruikt voor onder meer het drenken van vee en voor het reinigen van stallen. Ook wordt er oppervlakte- en grondwater gebruikt voor het beregenen van gewassen. De mate waarin oppervlakte- en grondwater wordt gebruikt, wordt vooral bepaald door de weersomstandigheden: in droge jaren wordt er meer beregend dan in natte jaren.

Ten behoeve van de CBS-publicaties Milieurekeningen, Monitor Brede Welvaart en het Compendium voor de Leefomgeving levert Wageningen Economic Research cijfers aan het CBS met betrekking tot het watergebruik in de agrarische sector. Deze nota is een actualisatie van de eerder verschenen nota's Watergebruik in de land- en tuinbouw (onder andere Van der Meer, 2018).

\subsection{Resultaat}

Deze nota beschrijft het watergebruik in 2017 en 2018 van 5 land- en tuinbouwsectoren in 7 stroomgebieden in Nederland (zie paragraaf 2.2). Hierbij worden onderstaande typen water onderscheiden:

- leidingwater (drenking en overig)

- gietwater

- grondwater voor irrigatie

- oppervlaktewater voor irrigatie

- grond-/oppervlakte water voor drenking.

Het watergebruik wordt bepaald voor de sector als geheel. Ook wordt het gemiddelde gebruik per bedrijf berekend. Daarnaast wordt het beregende areaal gerapporteerd.

\subsection{Afbakening}

Deze nota beschrijft hoe de berekeningen van Wageningen Economic Research hebben plaatsgevonden (hoofdstuk 2). De uitkomsten van de berekeningen (hoofdstuk 3) zijn de basis voor verdere verwerking door het CBS, en worden niet nader toegelicht in deze nota. Deze nota dient gezien te worden als een achtergronddocument ten behoeve van de opdrachtgever. De rapportage heeft betrekking op de jaren 2017 en 2018. Voor voorgaande jaren zijn eerdere rapportages verschenen. 


\section{$2 \quad$ Methodiek}

\section{$2.1 \quad$ Inleiding}

Dit hoofdstuk beschrijft de gehanteerde methode en uitgangspunten voor het bepalen van het watergebruik van de totale land- en tuinbouwsector. De berekening van het watergebruik vindt plaats op basis van de resultaten van de steekproefbedrijven in het Bedrijveninformatienet van Wageningen Economic Research. In het Bedrijveninformatienet wordt de gebruikte hoeveelheid water vastgelegd. Door de uitkomsten van de steekproefbedrijven te wegen kan een schatting worden gemaakt van het watergebruik van de totale steekproefpopulatie. De wegingsfactoren worden met behulp van statistical matching bepaald. Omdat het CBS het watergebruik wil weten van de totale agrarische sector wordt een bijschatting gemaakt. Deze gaat over de bedrijven die buiten het steekproefkader van Wageningen Economic Research vallen en daardoor niet gerepresenteerd worden in de steekproef (zie paragraaf 2.4).

\subsection{Bedrijfstypen en stroomgebieden}

Het watergebruik wordt voor 5 landbouwsectoren bepaald:

- akkerbouw

- fruitteelt

- tuinbouw (opengrondstuinbouw en glastuinbouw exclusief fruitteelt)

- veehouderij

- overige landbouw.

De stroomgebieden die worden onderscheiden staan in figuur 2.1.

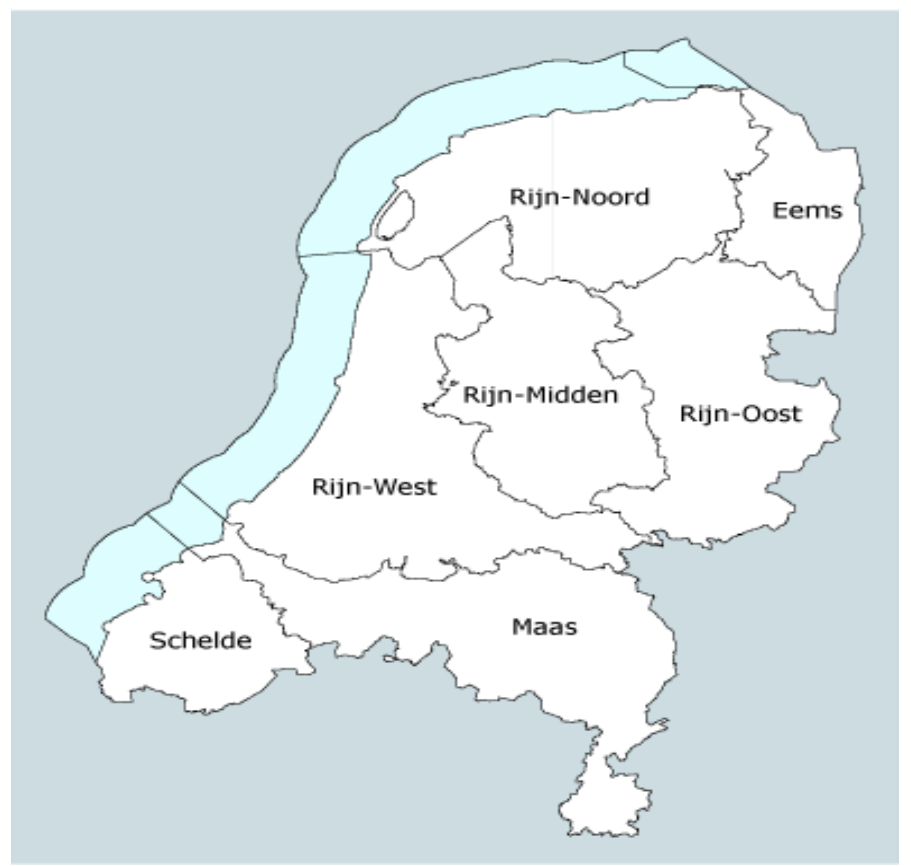

Figuur 2.1 Stroomgebieden van Nederland

Bron: CBS. 


\subsection{Statistical matching}

Het CBS wil een uitsplitsing van het watergebruik naar de verschillende agrarische sectoren en naar de diverse stroomgebieden. Hierbij is het gewenst om rekening te houden met de structuur en de productieomstandigheden van de bedrijven in de afzonderlijke stroomgebieden. De basis van deze analyse zijn de bedrijven uit het Bedrijveninformatienet van Wageningen Economic Research (zie voor meer achtergrondinformatie over de samenstelling van de steekproef het rapport van Van der Meer et al., 2019). De steekproef is een disproportionele steekproef waardoor insluitingskansen voor bedrijven binnen een sector niet gelijk zijn. Hier wordt rekening mee gehouden door gewichten toe te kennen aan de bedrijven. Vervolgens kunnen de resultaten van de steekproefbedrijven worden opgeschaald naar de totale steekproefpopulatie met behulp van deze wegingsfactoren. De standaardwegingsfactoren in het Bedrijveninformatienet houden geen rekening met het stroomgebied waarin het bedrijf gevestigd is. Dit kan ertoe leiden dat als de standaardwegingsfactoren worden gebruikt, de gemiddelde bedrijfsstructuur van de steekproefbedrijven afwijkt van de daadwerkelijke gemiddelde structuur van de bedrijven in het stroomgebied. Met behulp van statistical matching worden wegingsfactoren bepaald die wel rekening houden met de regio waarin het bedrijf gevestigd is (zie bijlage 4 voor de achtergronden). Bij statistical matching worden steekproefbedrijven (Bedrijveninformatienet) gekoppeld aan bedrijven uit de steekproefpopulatie (Landbouwtelling). De koppeling vindt plaats op basis van kenmerken die zowel in de Landbouwtelling als in het Bedrijveninformatienet worden vastgelegd. De kenmerken waarop gekoppeld wordt, worden de matchingvariabelen genoemd. De mate van overeenkomst tussen de gekoppelde bedrijven, bepaalt de hoogte van de wegingsfactor. Er zijn zes kenmerken gebruikt voor de matching; tabel 2.1 geeft de gehanteerde matchingvariabelen.

Tabel 2.1 Kenmerken warop statistical matching plaatsvindt

\begin{tabular}{ll} 
Exact te matchen: & Best passend: \\
\hline Jaar & X en Y coördinaten van het bedrijf \\
\hline Bedrijfstype & Grondsoort \\
\hline & Aantal ha \\
\hline & Bedrijfsomvang in Standaardopbrengst \\
\hline
\end{tabular}

Voor matching tussen steekproefbedrijven en bedrijven uit de populatie komen alleen bedrijven in aanmerking uit hetzelfde jaar en die van hetzelfde bedrijfstype zijn. Uit deze 'pools' worden vervolgens de drie bedrijven geselecteerd met een zo gelijk mogelijk areaal (ha), grondsoort en economische omvang gemeten in euro Standaardopbrengst (SO). Het bedrijf dat hemelsbreed (op basis van X- en $\mathrm{Y}$ coördinaten) het dichtst bij het te matchen bedrijf ligt, krijgt daarbij een hogere weging dan bedrijven die op grotere afstand liggen. Er is gekozen voor deze matchingvariabelen, omdat het watergebruik afhankelijk is van zowel de omvang van het bedrijf als de intensiteit van de productie. Omdat neerslag lokaal sterk kan verschillen, speelt ook de locatie van het bedrijf een belangrijke rol bij de matching. Dit geldt vooral voor de bedrijven die beregenen. Het kan daarom voorkomen dat een bedrijf gematcht wordt aan een bedrijf in de nabijheid, met dezelfde grondsoort maar net in een ander stroomgebied ligt. Aangenomen is dat dit een betere voorspeller is voor het watergebruik dan een match met een bedrijf dat weliswaar in hetzelfde stroomgebied ligt maar wel tientallen kilometers verderop.

Voor het landbouwtellingsbedrijf wordt het watergebruik geschat op basis van de gematchte bedrijven uit het Informatienet. Van de bedrijven uit het Informatienet wordt het watergebruik per SO bepaald. Het watergebruik van het landbouwtellingsbedrijf wordt benaderd door het watergebruik per SO te vermenigvuldigen met zijn eigen omvang gemeten in SO zoals is vastgelegd in de Landbouwtelling. Het areaal met beregening wordt bepaald door het aandeel van het areaal met beregening in het totale areaal van de bedrijven uit het Informatienet te berekenen. Vervolgens wordt het aandeel van het gematchte bedrijf vermenigvuldigd met het areaal van het landbouwtellingsbedrijf. Het beregende areaal wordt bepaald door het aantal keren dat er beregend is te berekenen op de bedrijven uit het Informatienet. Verondersteld is dat het landbouwtellingsbedrijf hetzelfde aantal keren beregent als het gematchte bedrijf. Ten slotte worden de resultaten van de landbouwtellingsbedrijven per stroomgebied geaggregeerd om tot totalen te komen voor de stroomgebieden. 


\section{$2.4 \quad$ Bijschatting}

Als het watergebruik van de steekproefpopulatie is bepaald, wordt er een bijschatting gemaakt. Een deel van de populatie wordt niet door de steekproef gerepresenteerd, omdat de steekproef een ondergrens kent van 25.000 euro SO. De bijschatting vindt plaats op basis van het gemiddelde watergebruik per SO per bedrijfstype per stroomgebied.

\subsection{Drenking vee}

Het water dat gebruikt wordt voor de drenking van het vee wordt geschat op basis van normen van het watergebruik per dier (KWIN 2009). Daarnaast worden de volgende uitgangspunten gehanteerd. Voor rundveedrenking is grondwater veel belangrijker dan oppervlaktewater, vanwege de min of meer constante waterkwaliteit. Alleen voor de diergroep rundvee wordt oppervlakte- en grondwater gebruikt naast de drenking met leidingwater. Er kan alleen oppervlakte-/grondwater worden gebruikt voor drenking als er of een boorput, of een hydrofoor of een veevelddrinkwaterinstallatie op het bedrijf aanwezig is.

Het vee kan in de praktijk ook rechtstreeks uit het oppervlaktewater drinken zonder dat bovenstaande installaties aanwezig zijn. Of dit inderdaad het geval is, is niet bekend en wordt daarom niet meegenomen in de berekening. Dit geeft mogelijk een onderschatting van de gebruikte hoeveelheid oppervlaktewater c.q. een overschatting van de hoeveelheid leidingwater gebruikt voor drenking.

Indien op een bedrijf naast rundvee ook andere dieren worden gehouden, dan wordt voor drenking van de overige dieren een normatieve hoeveelheid leidingwater berekend. Deze berekende hoeveelheid leidingwater wordt in mindering gebracht op de totaal gebruikte hoeveelheid leidingwater. Dit totale leidingwatergebruik wordt geregistreerd op basis van de afrekening van het waterbedrijf en gecorrigeerd voor huishoudelijk gebruik. Resteert er dan nog leidingwater, dan is verondersteld dat het rundvee dit voor drenking heeft gebruikt. Deze hoeveelheid water wordt in mindering gebracht op de berekende hoeveelheid voor drenking gebruikt oppervlakte- en grondwater, zoals bepaald in de vorige stap.

Voor het schoonmaken van de stallen (KWIN, 2009) en voor het gebruik van de melkrobot (Veehouderijtechniek, 2007) wordt normatief een gebruik aan leidingwater ingerekend. 


\section{Uitkomsten}

\subsection{Totaal watergebruik land- en tuinbouw}

Tabel 3.1 toont het watergebruik in de agrarische sector in 2017 en 2018 (een overzicht van de diverse jaren is weergegeven in bijlage 1 , een uitsplitsing naar sector en stroomgebied is te vinden in bijlage 2). In 2018 werd als gevolg van de record droogte een record hoeveelheid water gebruikt op de land- en tuinbouwbedrijven. Het gebruik lag op 350 miljoen $\mathrm{m}^{3}$. Er is een groter areaal beregend en de percelen zijn vaker beregend dan gebruikelijk. Hierdoor nam het gebruik van oppervlakte- en grondwater sterk toe. In 2018 waren er in meerdere regio's tijdelijke beregeningsverboden van kracht. Indien de beregeningsverboden niet waren afgekondigd zou het waterverbruik (vooral oppervlaktewater, maar ook grondwater) nog hoger zijn geweest. De stijging van het leidingwatergebruik in 2018 ten opzichte van 2017 was veel beperkter. In 2017 werd 168 miljoen m³ water gebruikt.

Tabel 3.1 Watergebruik $\left(1.000 \mathrm{~m}^{3}\right)$ in 2017 en 2018

\begin{tabular}{lrr} 
& 2017 & 2018 \\
Leidingwater & 48.248 & 48.764 \\
\hline W.v. drenking vee & 27.288 & 26.202 \\
\hline w.v. overig & 20.960 & 22.562 \\
\hline Gietwater & 1.072 & 1.270 \\
\hline Grondwater (irrigatie) & 68.159 & 198.182 \\
\hline Oppervlaktewater (irrigatie) & 12.048 & 66.434 \\
\hline Oppervlakte- of grondwater (drenking) & 38.435 & 36.285 \\
\hline Totaal & 167.963 & 350.934 \\
\hline
\end{tabular}

Bron: Bedrijveninformatienet en CBS Landbouwtelling, berekeningen Wageningen Economic Research.

De cijfers in tabel 3.1 zijn de totalen na bijschatting. In tabel 3.2 is weergegeven welk deel van het watergebruik is bijgeschat (zie 2.4) voor bedrijven die buiten het steekproefkader van Wageningen Economic Research vallen. Voor beide jaren ligt de bijschatting op ruim $1 \%$.

Tabel 3.2 Bijschatting watergebruik 2017 en 2018 (\%)

\begin{tabular}{lll} 
& 2017 & 2,18 \\
Leidingwater totaal & 2,9 & 2,6 \\
\hline Leidingwater drenking vee & 2,5 & 2,4 \\
\hline Gietwater & 0,0 & 0,0 \\
\hline Grondwater (irrigatie) & 1,3 & 1,5 \\
\hline Oppervlaktewater (irrigatie) & 0,7 & 0,0 \\
\hline Oppervlakte- of grondwater (drenking) & 0,0 & 0,1 \\
\hline Totaal & 1,4 & 1,2 \\
\hline
\end{tabular}

Bron: Bedrijveninformatienet en CBS Landbouwtelling, berekeningen Wageningen Economic Research. 


\subsection{Watergebruik per bedrijf}

In tabel 3.3 wordt het totale jaarlijkse gemiddelde watergebruik per bedrijf weergegeven. In 2017 werd er gemiddeld ruim $3.000 \mathrm{~m}^{3}$ water per bedrijf gebruikt, waarvan bijna $900 \mathrm{~m}^{3}$ leidingwater. In 2018 nam het gebruik als gevolg van de droogte sterk toe. Het totale watergebruik verdubbelde ten opzichte van 2017. De hoeveelheid leidingwater die werd gebruikt, nam veel minder sterk toe (in bijlage 3 is een uitsplitsing per bedrijfstype weergegeven). De toename van het gebruik is toe te schrijven aan het extra watergebruik voor beregening.

Tabel 3.3 Gemiddeld watergebruik $\left(\mathrm{m}^{3}\right)$ per bedrijf, naar stroomgebied, 2017 en 2018

\begin{tabular}{|c|c|c|c|}
\hline Stroomgebied & Water & 2017 & 2018 \\
\hline \multirow[t]{2}{*}{ Eems } & Gemiddeld totaal water & 2.662 & 7.213 \\
\hline & w.v. leidingwater & 837 & 845 \\
\hline Rijn - Noord & w.v. leidingwater & 1.386 & 1.415 \\
\hline Rijn - Oost & Gemiddeld totaal water & 2.475 & 5.859 \\
\hline \multirow[t]{2}{*}{ Rijn - Midden } & Gemiddeld totaal water & 2.593 & 7.416 \\
\hline & w.v. leidingwater & 617 & 659 \\
\hline \multirow[t]{2}{*}{ Rijn - West } & Gemiddeld totaal water & 1.753 & 4.015 \\
\hline & w.v. leidingwater & 730 & 796 \\
\hline Maas & w.v. leidingwater & 1.125 & 1.089 \\
\hline \multirow[t]{2}{*}{ Totaal } & Gemiddeld totaal water & 3.063 & 6.519 \\
\hline & w.v. leidingwater & 880 & 906 \\
\hline
\end{tabular}

Bron: Bedrijveninformatienet en CBS Landbouwtelling, berekeningen Wageningen Economic Research. 


\subsection{Beregend areaal}

Tabel 3.4 toont het beregende areaal en het areaal met beregening. Zoals verwacht is het areaal dat minimaal 1 keer beregend is veel hoger dan in 2017, namelijk bijna 300.000 ha. Daarnaast is er ook vaker beregend dan het jaar ervoor, zodat het beregende areaal in 2018 boven de 1 miljoen hectare lag. In 2017 bedroeg het beregende areaal ruim 16.000 ha.

Tabel 3.4 Beregend areaal (ha) naar stroomgebied, $2017^{1}$ en 2018

\begin{tabular}{|c|c|c|c|}
\hline Stroomgebied & Beregening & 2017 & 2018 \\
\hline \multirow[t]{2}{*}{ Eems } & Areaal minimaal 1 keer beregend & 6.935 & 13.297 \\
\hline & Beregend areaal & 11.725 & 52.975 \\
\hline Rijn - Noord & Beregend areaal & 8.820 & 50.709 \\
\hline Rijn - Oost & Areaal minimaal 1 keer beregend & 22.222 & 57.626 \\
\hline \multirow[t]{2}{*}{ Rijn - Midden } & Areaal minimaal 1 keer beregend & 16.684 & 47.737 \\
\hline & Beregend areaal & 31.551 & 149.036 \\
\hline \multirow[t]{2}{*}{ Rijn - West } & Areaal minimaal 1 keer beregend & 14.222 & 41.364 \\
\hline & Beregend areaal & 26.891 & 140.883 \\
\hline Maas & Beregend areaal & 161.722 & 471.296 \\
\hline \multirow[t]{2}{*}{ Totaal } & Areaal minimaal 1 keer beregend & 142.773 & 296.856 \\
\hline & Beregend areaal & 302.140 & 1.150 .359 \\
\hline
\end{tabular}

Bron: Bedrijveninformatienet en CBS Landbouwtelling, berekeningen Wageningen Economic Research.

\footnotetext{
${ }^{1}$ In de oorspronkelijke publicatie waren de resultaten voor 2017 door een technische fout onjuist weergegeven, deze zijn in deze versie gecorrigeerd.
} 


\section{Literatuur en websites}

Meer, van der, R.W., 2018, Watergebruik in de land- en tuinbouw 2015 en 2016. Wageningen Economic Research nota 2018-105.

Meer, van der, R.W., L. Ge and H.B. van der Veen, 2019, Sample for the Dutch FADN 2016.

Wageningen Economic Research report 2019-020. The Hague: Wageningen Economic Research.

Slingerland, R., 2007. Lely Astronaut A3: Robot met 'brains and feelings'. In: Veehouderij techniek, november.

Vrolijk, H.C.J., W. Dol en T. Kuhlman, 2005. Integration of small area estimation and mapping techniques - Tool for regional studies. LEI report 8.05.01. The Hague: LEI.

Wageningen UR Livestock Research, 2009. Kwantitatieve Informatie Veehouderij (KWIN) 2009 - 2010. Lelystad: Wageningen UR Livestock Research. 


\section{Bijlage 1 Watergebruik vanaf 2001}

Tabel B1.1 Watergebruik (in m/n. $\mathrm{m}^{3}$ ), 2001-2018

\begin{tabular}{|c|c|c|c|c|c|c|c|}
\hline & Leidingwater & Gietwater & $\begin{array}{r}\text { Grondwater } \\
\text { (irrigatie) }\end{array}$ & $\begin{array}{r}\text { Oppervlakte- } \\
\text { of grondwater } \\
\text { (irrigatie) }\end{array}$ & $\begin{array}{r}\text { Oppervlakte- } \\
\text { water } \\
\text { (irrigatie) }\end{array}$ & $\begin{array}{l}\text { Oppervlakte- } \\
\text { of grondwater } \\
\text { (drenking) }\end{array}$ & Totaal \\
\hline 2001 & 50 & 0 & 23 & 8 & 12 & 39 & 132 \\
\hline 2002 & 50 & 3 & 23 & 8 & 12 & 38 & 134 \\
\hline 2003 & 57 & 6 & 101 & 22 & 32 & 38 & 256 \\
\hline 2004 & 50 & 4 & 23 & 9 & 13 & 38 & 137 \\
\hline 2005 & 47 & 3 & 24 & 6 & 6 & 36 & 122 \\
\hline 2006 & 46 & 1 & 62 & 12 & 15 & 32 & 168 \\
\hline 2007 & 46 & 3 & 19 & 9 & 9 & 33 & 118 \\
\hline 2008 & 44 & 2 & 19 & 8 & 8 & 36 & 116 \\
\hline 2009 & 47 & 2 & 39 & 8 & 6 & 37 & 140 \\
\hline 2010 & 44 & 2 & 54 & 12 & 14 & 40 & 166 \\
\hline 2011 & 43 & 2 & 60 & 0 & 19 & 38 & 162 \\
\hline 2012 & 39 & 1 & 18 & 1 & 3 & 37 & 99 \\
\hline 2013 & 41 & 1 & 53 & - & 13 & 39 & 148 \\
\hline 2014 & 42 & 1 & 30 & - & 10 & 41 & 125 \\
\hline 2015 & 43 & 1 & 49 & - & 19 & 37 & 148 \\
\hline 2016 & 43 & 1 & 28 & - & 10 & 38 & 120 \\
\hline 2017 & 48 & 1 & 68 & - & 12 & 38 & 168 \\
\hline 2018 & 49 & 1 & 198 & - & 66 & 36 & 350 \\
\hline
\end{tabular}

Bron: Watergebruik in de agrarische sector/Watergebruik in de land- en tuinbouw (diverse edities). 


\section{Bijlage 2 Watergebruik naar sector en stroomgebied}

Tabellen B2.2a en B2.2b laten het totale geschatte watergebruik per stroomgebied en sector zien in 2017 en 2018.

Tabel B2.2a Watergebruik $\left(1.000 \mathrm{~m}^{3}\right)$ naar sector en stroomgebied, 2017

\begin{tabular}{|c|c|c|c|c|c|c|c|}
\hline $\begin{array}{l}\text { Stroom- } \\
\text { gebied }\end{array}$ & Watergebruik & $\begin{array}{l}\text { Akker- } \\
\text { bouw }\end{array}$ & $\begin{array}{l}\text { Tuin- } \\
\text { bouw }\end{array}$ & Fruit & $\begin{array}{c}\text { Vee- } \\
\text { houderij }\end{array}$ & $\begin{array}{r}\text { Overig } \\
\text { landbouw }\end{array}$ & Totaal \\
\hline \multirow[t]{8}{*}{ Eems } & Leidingwater & 90 & 33 & 1 & 1.505 & 135 & 1.763 \\
\hline & w.v. drenking vee & 22 & 0 & 0 & 1.205 & 84 & 1.312 \\
\hline & w.v. overig & 68 & 33 & 1 & 300 & 51 & 451 \\
\hline & Gietwater & 0 & 8 & 0 & 0 & 0 & 8 \\
\hline & Grondwater (irrigatie) & 434 & 105 & 0 & 380 & 278 & 1.196 \\
\hline & Oppervlaktewater (irrigatie) & 990 & 17 & 0 & 49 & 24 & 1.080 \\
\hline & Oppervlakte- of grondwater (drenking) & 6 & 1 & 0 & 1.513 & 38 & 1.558 \\
\hline & Totaal water & 1.520 & 163 & 1 & 3.447 & 475 & 5.605 \\
\hline \multirow[t]{8}{*}{ Rijn - Noord } & Leidingwater & 158 & 59 & 1 & 7.585 & 89 & 7.892 \\
\hline & w.v. drenking vee & 37 & 0 & 0 & 6.229 & 55 & 6.321 \\
\hline & w.v. overig & 121 & 59 & 1 & 1.356 & 34 & 1.571 \\
\hline & Gietwater & 0 & 2 & 0 & 0 & 0 & 2 \\
\hline & Grondwater (irrigatie) & 803 & 69 & 0 & 477 & 145 & 1.495 \\
\hline & Oppervlaktewater (irrigatie) & 178 & 22 & 0 & 154 & 19 & 373 \\
\hline & Oppervlakte- of grondwater (drenking) & 16 & 2 & 0 & 6.727 & 36 & 6.781 \\
\hline & Totaal water & 1.156 & 153 & 1 & 14.944 & 290 & 16.543 \\
\hline \multirow[t]{8}{*}{ Rijn - Oost } & Leidingwater & 132 & 333 & 4 & 8.089 & 289 & 8.848 \\
\hline & w.v. drenking vee & 37 & 3 & 0 & 5.240 & 171 & 5.452 \\
\hline & w.v. overig & 95 & 330 & 4 & 2.849 & 118 & 3.396 \\
\hline & Gietwater & 0 & 201 & 0 & 0 & 0 & 201 \\
\hline & Grondwater (irrigatie) & 1.773 & 606 & 8 & 5.613 & 484 & 8.483 \\
\hline & Oppervlaktewater (irrigatie) & 461 & 143 & 4 & 833 & 57 & 1.498 \\
\hline & Oppervlakte- of grondwater (drenking) & 12 & 21 & 0 & 11.800 & 75 & 11.908 \\
\hline & Totaal water & 2.378 & 1.304 & 16 & 26.336 & 905 & 30.938 \\
\hline \multirow[t]{8}{*}{ Rijn - Midden } & Leidingwater & 302 & 158 & 17 & 2.633 & 129 & 3.239 \\
\hline & w.v. drenking vee & 92 & 1 & 0 & 1.692 & 75 & 1.860 \\
\hline & w.v. overig & 210 & 157 & 17 & 941 & 54 & 1.379 \\
\hline & Gietwater & 0 & 41 & 0 & 0 & 0 & 41 \\
\hline & Grondwater (irrigatie) & 2.444 & 212 & 0 & 1.586 & 446 & 4.687 \\
\hline & Oppervlaktewater (irrigatie) & 1.254 & 92 & 0 & 291 & 99 & 1.736 \\
\hline & Oppervlakte- of grondwater (drenking) & 88 & 3 & 0 & 3.730 & 89 & 3.909 \\
\hline & Totaal water & 4.088 & 506 & 17 & 8.239 & 764 & 13.613 \\
\hline \multirow[t]{8}{*}{ Rijn - West } & Leidingwater & 326 & 1.845 & 193 & 6.606 & 103 & 9.073 \\
\hline & w.v. drenking vee & 84 & 5 & 0 & 4.869 & 54 & 5.012 \\
\hline & w.v. overig & 242 & 1.840 & 193 & 1.737 & 49 & 4.061 \\
\hline & Gietwater & 0 & 38 & 29 & 0 & 0 & 67 \\
\hline & Grondwater (irrigatie) & 1.250 & 1.321 & 1 & 1.216 & 167 & 3.954 \\
\hline & Oppervlaktewater (irrigatie) & 1.179 & 289 & 0 & 763 & 48 & 2.279 \\
\hline & Oppervlakte- of grondwater (drenking) & 86 & 55 & 0 & 6.184 & 80 & 6.404 \\
\hline & Totaal water & 2.841 & 3.548 & 222 & 14.768 & 398 & 21.777 \\
\hline
\end{tabular}




\begin{tabular}{|c|c|c|c|c|c|c|c|}
\hline $\begin{array}{l}\text { Stroom- } \\
\text { gebied }\end{array}$ & Watergebruik & $\begin{array}{l}\text { Akker- } \\
\text { bouw }\end{array}$ & $\begin{array}{l}\text { Tuin- } \\
\text { bouw }\end{array}$ & Fruit & $\begin{array}{r}\text { Vee- } \\
\text { houderij }\end{array}$ & $\begin{array}{r}\text { Overig } \\
\text { Iandbouw }\end{array}$ & Totaal \\
\hline \multirow[t]{8}{*}{ Schelde } & Leidingwater & 437 & 76 & 597 & 718 & 68 & 1.895 \\
\hline & w.v. drenking vee & 59 & 0 & 0 & 512 & 38 & 609 \\
\hline & w.v. overig & 378 & 76 & 597 & 206 & 30 & 1.286 \\
\hline & Gietwater & 0 & 1 & 485 & 0 & 0 & 485 \\
\hline & Grondwater (irrigatie) & 1.583 & 432 & 0 & 385 & 390 & 2.790 \\
\hline & Oppervlaktewater (irrigatie) & 2.174 & 64 & 0 & 91 & 31 & 2.361 \\
\hline & Oppervlakte- of grondwater (drenking) & 26 & 0 & 0 & 391 & 20 & 437 \\
\hline & Totaal water & 4.219 & 573 & 1.081 & 1.585 & 510 & 7.969 \\
\hline \multirow[t]{8}{*}{ Maas } & Leidingwater & 514 & 1.033 & 136 & 13.429 & 426 & 15.538 \\
\hline & w.v. drenking vee & 144 & 3 & 0 & 6.342 & 233 & 6.722 \\
\hline & w.v. overig & 370 & 1.030 & 136 & 7.087 & 193 & 8.816 \\
\hline & Gietwater & 0 & 209 & 59 & 0 & 0 & 268 \\
\hline & Grondwater (irrigatie) & 8.989 & 9.104 & 58 & 24.904 & 2.498 & 45.553 \\
\hline & Oppervlaktewater (irrigatie) & 1.573 & 625 & 29 & 316 & 177 & 2.720 \\
\hline & Oppervlakte- of grondwater (drenking) & 184 & 45 & 0 & 6.774 & 434 & 7.437 \\
\hline & Totaal water & 11.260 & 11.017 & 282 & 45.423 & 3.535 & 71.517 \\
\hline \multirow[t]{8}{*}{ Totaal } & Leidingwater & 1.959 & 3.536 & 948 & 40.564 & 1.241 & 48.248 \\
\hline & w.v. drenking vee & 475 & 12 & 0 & 26.089 & 711 & 27.288 \\
\hline & w.v. overig & 1.484 & 3.524 & 948 & 14.475 & 530 & 20.960 \\
\hline & Gietwater & 0 & 500 & 572 & 0 & 0 & 1.072 \\
\hline & Grondwater (irrigatie) & 17.275 & 11.848 & 67 & 34.561 & 4.409 & 68.159 \\
\hline & Oppervlaktewater (irrigatie) & 7.810 & 1.252 & 34 & 2.498 & 454 & 12.048 \\
\hline & Oppervlakte- of grondwater (drenking) & 418 & 128 & 0 & 37.119 & 771 & 38.435 \\
\hline & Totaal water & 27.462 & 17.264 & 1.621 & 114.741 & 6.875 & 167.963 \\
\hline
\end{tabular}

Bron: Bedrijveninformatienet en CBS Landbouwtelling. berekeningen Wageningen Economic Research. 
Tabel B2.2b Watergebruik $\left(1.000 \mathrm{~m}^{3}\right)$ naar sector en stroomgebied, 2018

\begin{tabular}{|c|c|c|c|c|c|c|c|}
\hline $\begin{array}{l}\text { Stroom- } \\
\text { gebied }\end{array}$ & Watergebruik & $\begin{array}{l}\text { Akker- } \\
\text { bouw }\end{array}$ & $\begin{array}{l}\text { Tuin- } \\
\text { bouw }\end{array}$ & Fruit & $\begin{array}{r}\text { Vee- } \\
\text { houderij }\end{array}$ & $\begin{array}{r}\text { Overig } \\
\text { landbouw }\end{array}$ & Totaal \\
\hline \multirow[t]{6}{*}{ Eems } & Leidingwater & 116 & 44 & 1 & 1.490 & 110 & 1.760 \\
\hline & w.v. overig & 89 & 44 & 1 & 292 & 47 & 471 \\
\hline & Gietwater & 0 & 27 & 0 & 0 & 0 & 27 \\
\hline & Oppervlaktewater (irrigatie) & 5.562 & 17 & 0 & 246 & 213 & 6.037 \\
\hline & Oppervlakte- of grondwater (drenking) & 6 & 0 & 0 & 1.482 & 14 & 1.502 \\
\hline & Totaal water & 8.409 & 187 & 1 & 5.996 & 424 & 15.017 \\
\hline \multirow[t]{5}{*}{ Rijn - Noord } & Leidingwater & 179 & 65 & 1 & 7.590 & 79 & 7.915 \\
\hline & Grondwater (irrigatie) & 2.547 & 110 & 1 & 4.112 & 104 & 6.874 \\
\hline & Oppervlaktewater (irrigatie) & 1.644 & 48 & 0 & 3.057 & 169 & 4.917 \\
\hline & Oppervlakte- of grondwater (drenking) & 5 & 0 & 0 & 6.520 & 18 & 6.543 \\
\hline & Totaal water & 4.374 & 226 & 2 & 21.279 & 370 & 26.252 \\
\hline \multirow[t]{5}{*}{ Rijn - Oost } & Leidingwater & 156 & 274 & 6 & 8.241 & 250 & 8.927 \\
\hline & w.v. drenking vee & 37 & 2 & 0 & 5.093 & 140 & 5.272 \\
\hline & w.v. overig & 119 & 272 & 6 & 3.148 & 110 & 3.655 \\
\hline & Gietwater & 0 & 144 & 1 & 0 & 0 & 145 \\
\hline & Grondwater (irrigatie) & 8.644 & 1.442 & 11 & 34.104 & 1.074 & 45.276 \\
\hline \multirow{6}{*}{ Rijn - Midden } & w.v. overig & 283 & 191 & 19 & 957 & 74 & 1.524 \\
\hline & Gietwater & 0 & 51 & 2 & 0 & 0 & 53 \\
\hline & Grondwater (irrigatie) & 14.239 & 767 & 0 & 6.999 & 821 & 22.827 \\
\hline & Oppervlaktewater (irrigatie) & 6.504 & 157 & 0 & 1.018 & 702 & 8.381 \\
\hline & Oppervlakte- of grondwater (drenking) & 60 & 0 & 0 & 3.730 & 61 & 3.850 \\
\hline & Totaal water & 21.191 & 1.166 & 21 & 14.400 & 1.757 & 38.535 \\
\hline \multirow[t]{8}{*}{ Rijn - West } & Leidingwater & 369 & 2.254 & 227 & 6.683 & 106 & 9.639 \\
\hline & w.v. drenking vee & 94 & 5 & 0 & 4.830 & 53 & 4.981 \\
\hline & w.v. overig & 275 & 2.249 & 227 & 1.853 & 53 & 4.658 \\
\hline & Gietwater & 0 & 90 & 53 & 0 & 0 & 143 \\
\hline & Grondwater (irrigatie) & 5.149 & 3.350 & 0 & 6.944 & 636 & 16.079 \\
\hline & Oppervlaktewater (irrigatie) & 7.594 & 1.370 & 0 & 7.581 & 224 & 16.769 \\
\hline & Oppervlakte- of grondwater (drenking) & 53 & 44 & 0 & 5.826 & 45 & 5.968 \\
\hline & Totaal water & 13.165 & 7.108 & 280 & 27.035 & 1.011 & 48.598 \\
\hline \multirow[t]{3}{*}{ Schelde } & Leidingwater & 528 & 103 & 827 & 795 & 110 & 2.364 \\
\hline & w.v. drenking vee & 74 & 0 & 0 & 543 & 55 & 672 \\
\hline & w.v. overig & 454 & 103 & 827 & 252 & 55 & 1.692 \\
\hline
\end{tabular}




\begin{tabular}{|c|c|c|c|c|c|c|c|}
\hline $\begin{array}{l}\text { Stroom- } \\
\text { gebied }\end{array}$ & Watergebruik & $\begin{array}{r}\text { Akker- } \\
\text { bouw }\end{array}$ & $\begin{array}{l}\text { Tuin- } \\
\text { bouw }\end{array}$ & Fruit & $\begin{array}{r}\text { Vee- } \\
\text { houderij }\end{array}$ & $\begin{array}{r}\text { Overig } \\
\text { Iandbouw }\end{array}$ & Totaal \\
\hline \multirow[t]{8}{*}{ Maas } & Leidingwater & 1.003 & 1.343 & 164 & 11.723 & 503 & 14.735 \\
\hline & w.v. drenking vee & 192 & 4 & 0 & 5.325 & 292 & 5.812 \\
\hline & w.v. overig & 811 & 1.339 & 164 & 6.398 & 211 & 8.923 \\
\hline & Gietwater & 0 & 76 & 71 & 0 & 0 & 147 \\
\hline & Grondwater (irrigatie) & 22.483 & 13.016 & 76 & 51.854 & 7.299 & 94.728 \\
\hline & Oppervlaktewater (irrigatie) & 8.238 & 3.453 & 32 & 1.617 & 829 & 14.169 \\
\hline & Oppervlakte- of grondwater (drenking) & 185 & 60 & 0 & 6.220 & 362 & 6.828 \\
\hline & Totaal water & 31.908 & 17.948 & 343 & 71.415 & 8.994 & 130.608 \\
\hline \multirow[t]{8}{*}{ Totaal } & Leidingwater & 2.739 & 4.274 & 1.244 & 39.175 & 1.332 & 48.764 \\
\hline & w.v. drenking vee & 566 & 11 & 0 & 24.877 & 748 & 26.202 \\
\hline & w.v. overig & 2.173 & 4.263 & 1.244 & 14.298 & 584 & 22.562 \\
\hline & Gietwater & 0 & 394 & 876 & 0 & 0 & 1.270 \\
\hline & Grondwater (irrigatie) & 59.621 & 19.371 & 92 & 107.804 & 11.295 & 198.182 \\
\hline & Oppervlaktewater (irrigatie) & 40.287 & 5.878 & 38 & 17.320 & 2.910 & 66.434 \\
\hline & Oppervlakte- of grondwater (drenking) & 355 & 122 & 0 & 35.241 & 567 & 36.285 \\
\hline & Totaal water & 103.002 & 30.038 & 2.250 & 199.540 & 16.104 & 350.934 \\
\hline
\end{tabular}

Bron: Bedrijveninformatienet en CBS Landbouwtelling. berekeningen Wageningen Economic Research. 


\section{Bijlage 3 Watergebruik per bedrijf}

Onderstaande tabellen tonen het watergebruik per bedrijf naar type en stroomgebied in respectievelijk 2017 en 2018.

Tabel B3.3a Gemiddeld watergebruik $\left(m^{3}\right)$ per bedrijf. naar stroomgebied en bedrijfstype, 2017

\begin{tabular}{|c|c|c|c|c|c|c|c|}
\hline $\begin{array}{l}\text { Stroom- } \\
\text { gebied }\end{array}$ & Water & $\begin{array}{r}\text { Akker- } \\
\text { bouw }\end{array}$ & $\begin{array}{l}\text { Tuin- } \\
\text { bouw }\end{array}$ & Fruit & $\begin{array}{r}\text { Vee- } \\
\text { houderij }\end{array}$ & $\begin{array}{r}\text { Overig } \\
\text { landbouw }\end{array}$ & Totaal \\
\hline \multirow[t]{2}{*}{ Eems } & Gemiddeld totaal water & 1.493 & 2.233 & 125 & 3.746 & 5.455 & 2.662 \\
\hline & w.v. leidingwater & 88 & 445 & 83 & 1.636 & 1.555 & 837 \\
\hline \multirow[t]{2}{*}{ Rijn - Noord } & Gemiddeld totaal water & 1.552 & 1.389 & 99 & 3.133 & 4.832 & 2.905 \\
\hline & w.v. leidingwater & 212 & 539 & 60 & 1.590 & 1.490 & 1.386 \\
\hline \multirow[t]{2}{*}{ Rijn - Oost } & Gemiddeld totaal water & 1.224 & 3.033 & 347 & 2.696 & 2.901 & 2.475 \\
\hline & w.v. leidingwater & 68 & 774 & 97 & 828 & 927 & 708 \\
\hline \multirow[t]{2}{*}{ Rijn - Midden } & Gemiddeld totaal water & 3.072 & 1.715 & 214 & 2.393 & 7.414 & 2.593 \\
\hline & w.v. leidingwater & 227 & 535 & 214 & 765 & 1.257 & 617 \\
\hline \multirow[t]{2}{*}{ Rijn - West } & Gemiddeld totaal water & 1.821 & 967 & 310 & 2.350 & 2.040 & 1.753 \\
\hline & w.v. leidingwater & 209 & 503 & 269 & 1.051 & 529 & 730 \\
\hline \multirow[t]{2}{*}{ Schelde } & Gemiddeld totaal water & 2.157 & 2.616 & 4.159 & 3.262 & 3.861 & 2.610 \\
\hline & w.v. leidingwater & 223 & 346 & 2.295 & 1.477 & 515 & 621 \\
\hline \multirow[t]{2}{*}{ Maas } & Gemiddeld totaal water & 3.464 & 4.511 & 846 & 6.387 & 5.283 & 5.179 \\
\hline & w.v. leidingwater & 158 & 423 & 408 & 1.888 & 637 & 1.125 \\
\hline \multirow[t]{2}{*}{ Totaal } & Gemiddeld totaal water & 2.326 & 2.386 & 1.115 & 3.500 & 4.413 & 3.063 \\
\hline & w.v. leidingwater & 166 & 489 & 653 & 1.237 & 797 & 880 \\
\hline
\end{tabular}

Tabel B3.3b Gemiddeld watergebruik $\left(m^{3}\right)$ per bedrijf. naar stroomgebied en bedrijfstype, 2018

\begin{tabular}{|c|c|c|c|c|c|c|c|}
\hline $\begin{array}{l}\text { Stroom- } \\
\text { gebied }\end{array}$ & Water & $\begin{array}{l}\text { Akker- } \\
\text { bouw }\end{array}$ & $\begin{array}{l}\text { Tuin- } \\
\text { bouw }\end{array}$ & Fruit & $\begin{array}{r}\text { Vee- } \\
\text { houderij }\end{array}$ & $\begin{array}{r}\text { Overig } \\
\text { landbouw }\end{array}$ & Totaal \\
\hline \multirow[t]{2}{*}{ Eems } & Gemiddeld totaal water & 8.236 & 2.423 & 138 & 6.684 & 5.306 & 7.213 \\
\hline & w.v. leidingwater & 113 & 571 & 74 & 1.661 & 1.371 & 845 \\
\hline \multirow[t]{2}{*}{ Rijn - Noord } & Gemiddeld totaal water & 5.622 & 2.019 & 171 & 4.598 & 5.785 & 4.695 \\
\hline & w.v. leidingwater & 230 & 584 & 63 & 1.640 & 1.241 & 1.415 \\
\hline \multirow[t]{2}{*}{ Rijn - Oost } & Gemiddeld totaal water & 5.357 & 5.444 & 503 & 6.000 & 6.337 & 5.859 \\
\hline & w.v. leidingwater & 74 & 671 & 135 & 871 & 871 & 725 \\
\hline \multirow[t]{2}{*}{ Rijn - Midden } & Gemiddeld totaal water & 15.803 & 4.178 & 270 & 4.256 & 15.279 & 7.416 \\
\hline & w.v. leidingwater & 289 & 684 & 247 & 784 & 1.509 & 659 \\
\hline \multirow[t]{2}{*}{ Rijn - West } & Gemiddeld totaal water & 8.322 & 2.061 & 397 & 4.367 & 5.742 & 4.015 \\
\hline & w.v. leidingwater & 233 & 654 & 321 & 1.079 & 604 & 796 \\
\hline \multirow[t]{2}{*}{ Schelde } & Gemiddeld totaal water & 6.497 & 5.473 & 6.054 & 5.638 & 13.301 & 6.546 \\
\hline & w.v. leidingwater & 272 & 477 & 3.170 & 1.703 & 846 & 784 \\
\hline \multirow[t]{2}{*}{ Maas } & Gemiddeld totaal water & 9.611 & 7.519 & 1.062 & 10.445 & 13.648 & 9.656 \\
\hline & w.v. leidingwater & 302 & 562 & 506 & 1.715 & 764 & 1.089 \\
\hline \multirow[t]{2}{*}{ Totaal } & Gemiddeld totaal water & 8.513 & 4.336 & 1.573 & 6.262 & 10.658 & 6.519 \\
\hline & w.v. leidingwater & 226 & 617 & 870 & 1.229 & 882 & 906 \\
\hline
\end{tabular}




\section{Bijlage 4 Statistical matching}

Voor het bijschatten en wegen van de kengetallen worden de steekproefgegevens op de beschikbare gegevens over de steekproefpopulatie geprojecteerd. Wageningen Economic Research heeft hiervoor een statistical matchingsprocedure ontwikkeld. Als input worden twee datasets gemaakt. In de eerste dataset staan de bedrijven binnen de steekproefpopulatie (in dit geval de bedrijven in de Landbouwtelling binnen de steekproefgrens) met de karakteristieken waarmee de matching plaats gaat vinden. In de tweede dataset staan de steekproefbedrijven met dezelfde karakteristieken. De bedrijfskarakteristieken (ook wel matchingvariabelen genoemd) vormen de basis waarmee de steekproef- en populatiebedrijven vervolgens onderling worden vergeleken en gematcht.

Bij statistical matching worden de bedrijfskarakteristieken, die zowel in de steekproef als steekproefpopulatie bekend zijn, gebruikt om voor elk bedrijf in de steekproefpopulatie een aantal 'meest gelijkende' steekproefbedrijven af te leiden. Hierbij kan onderscheid worden gemaakt tussen kenmerken die exact overeen moeten komen en kenmerken van het steekproefbedrijf die zo gelijk mogelijk moeten zijn aan het bedrijf in de steekproefpopulatie. De 'zo gelijk mogelijk' te matchen kenmerken zijn door verschillende gewichten weer te onderscheiden naar belang. Elk bedrijf uit de steekproefpopulatie wordt gematcht met een aantal bedrijven uit de steekproef. Daarbij krijgt elk van die steekproefbedrijven een gewicht, optellend tot 1 . Het best bijpassende bedrijf krijgt het hoogste gewicht.

Per steekproefpopulatiebedrijf uit de Landbouwtelling worden vervolgens de watergebruiken per SO van de best bijpassende steekproefbedrijven vermenigvuldigd met de SO van het steekproefpopulatiebedrijf en de berekende gewichten. Zo kan elk steekproefpopulatiebedrijf een individuele schatting van een bedrijfskarakteristiek krijgen (in dit geval het watergebruik).

Centrale veronderstelling bij statistical matching is dat op basis van bedrijven die wat betreft de matchingvariabelen gelijk of zo gelijk mogelijk zijn, een schatting kan worden gemaakt van de doelvariabelen (in dit geval het watergebruik). 
Wageningen Economic Research Postbus 29703

2502 LS Den Haag

T 0703358330

Ecommunications.ssg@wur.nl

www.wur.nl/economic-research

Wageningen Economic Research NOTA

2020-030
De missie van Wageningen University \& Research is 'To explore the potential of nature to improve the quality of life'. Binnen Wageningen University \& Research bundelen Wageningen University en gespecialiseerde onderzoeksinstituten van Stichting Wageningen Research hun krachten om bij te dragen aan de oplossing van belangrijke vragen in het domein van gezonde voeding en leefomgeving. Met ongeveer 30 vestigingen, 5.000 medewerkers en 12.000 studenten behoort Wageningen University \& Research wereldwijd tot de aansprekende kennisinstellingen binnen haar domein. De integrale benadering van de vraagstukken en de samenwerking tussen verschillende disciplines vormen het hart van de unieke Wageningen aanpak. 



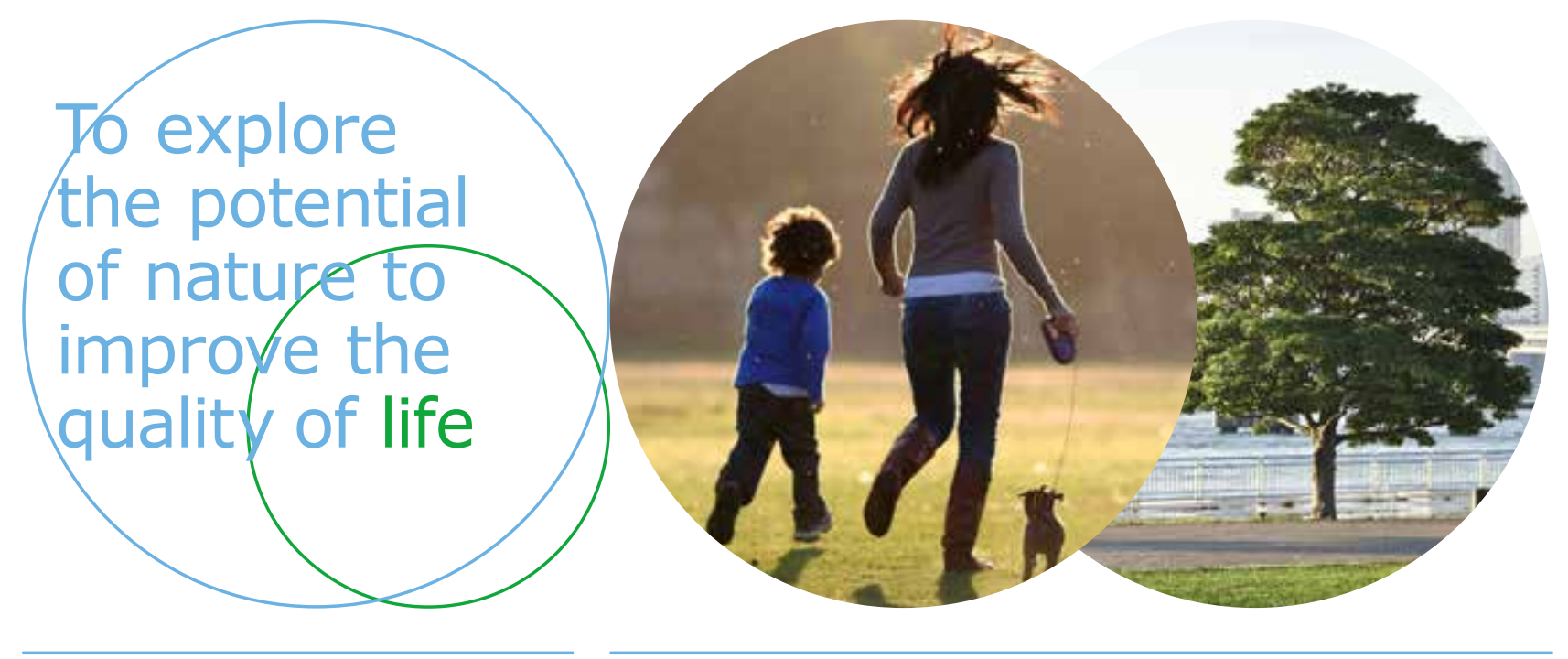

Wageningen Economic Research Postbus 29703

2502 LS Den Haag

T 0703358330

E communications.ssg@wur.nl www.wur.nl/economic-research

Nota $2020-030$
De missie van Wageningen University \& Research is 'To explore the potential of nature to improve the quality of life'. Binnen Wageningen University \& Research bundelen Wageningen University en gespecialiseerde onderzoeksinstituten van Stichting Wageningen Research hun krachten om bij te dragen aan de oplossing van belangrijke vragen in het domein van gezonde voeding en leefomgeving. Met ongeveer 30 vestigingen, 5.000 medewerkers en 12.000 studenten behoort Wageningen University \& Research wereldwijd tot de aansprekende kennisinstellingen binnen haar domein. De integrale benadering van de vraagstukken en de samenwerking tussen verschillende disciplines vormen het hart van de unieke Wageningen aanpak. 